Western University

Scholarship@Western

Biology Publications

Biology Department

$12-1-2015$

Linking energetics and overwintering in temperate insects.

Brent J Sinclair

bsincla7@uwo.ca

Follow this and additional works at: https://ir.lib.uwo.ca/biologypub

Part of the Biology Commons

Citation of this paper:

Sinclair, Brent J, "Linking energetics and overwintering in temperate insects." (2015). Biology Publications. 72.

https://ir.lib.uwo.ca/biologypub/72 


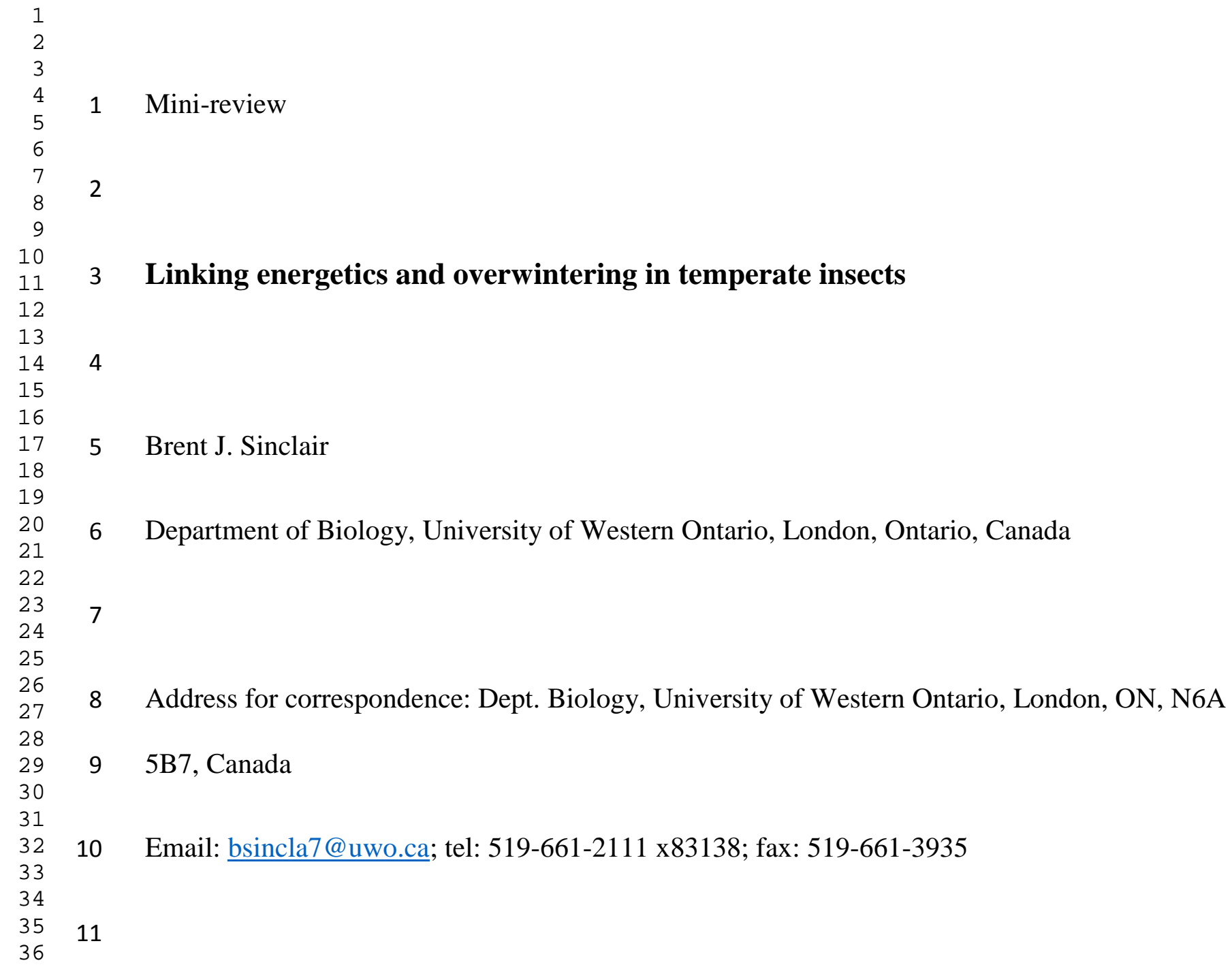

\section{$3 \quad$ Linking energetics and overwintering in temperate insects}

4

5 Brent J. Sinclair

6 Department of Biology, University of Western Ontario, London, Ontario, Canada

8 Address for correspondence: Dept. Biology, University of Western Ontario, London, ON, N6A

$9 \quad 5 B 7$, Canada

10 Email: bsincla7@uwo.ca; tel: 519-661-2111 x83138; fax: 519-661-3935 


\section{Abstract}

13 Overwintering insects cannot feed, and energy they take into winter must therefore fuel energy

14 demands during autumn, overwintering, warm periods prior to resumption of development in

15 spring, and subsequent activity. Insects primarily consume lipids during winter, but may also

16 use carbohydrate and proteins as fuel. Because they are ectotherms, the metabolic rate of insects

17 is temperature-dependent, and the curvilinear nature of the temperature-metabolic rate

18 relationship means that warm temperatures are disproportionately important to overwinter energy

19 use. This energy use may be reduced physiologically, by reducing the slope or elevation of the

20 temperature-metabolic rate relationship, or because of threshold changes, such as metabolic

21 suppression upon freezing. Insects may also choose microhabitats or life history stages that

22 reduce the impact of overwinter energy drain. There is considerable capacity for overwinter

23 energy drain to affect insect survival and performance both directly (via starvation) or indirectly

24 (for example, through a trade-off with cryoprotection), but this has not been well-explored.

25 Likewise, the impact of overwinter energy drain on growing-season performance is not well

26 understood. I conclude that overwinter energetics provides a useful lens through which to link

27 physiology and ecology and winter and summer in studies of insect responses to their

28 environment.

29

30 Keywords: Cold tolerance, Jensen's inequality, fat reserves, triglycerides, metabolic

31 suppression, diapause

32 
38 enter dormancy must fuel the mechanisms that protect against cold and desiccation, as well as

39 provide for basal metabolism throughout the period when the insect is dormant - which may

40 include parts of autumn and spring, as well as winter (Fig. 1). In the case of insects that

41 metamorphose or develop prior to feeding in the spring, the energy stores remaining after winter

42 must also fuel that development. If the adult stage does not feed (or has restricted nutrition),

43 remaining energy stores may represent all, or the majority of, the energy available for

44 reproduction. Because ectotherm metabolism is temperature-dependent, the energy remaining at

45 the end of the dormant period is determined by the thermal conditions experienced during winter

46 (and the adjacent portions of autumn and spring), and energy conservation is thus a general

47 requirement of overwintering that transcends variation in microhabitat, cold tolerance strategy

48 and developmental stage. In this mini-review, I will explore the factors that affect overwinter

49 energy use and conservation by temperate insects, with a view to exploring how growing-season

50 fitness might be determined by dormant-season energy use and conservation.

\section{2. Overwinter energy stores}

53 The juvenile stages of many insects have been selected to maximise growth, energy acquisition,

54 and storage to maximise the success of the adult stage (Boggs, 2009). Indeed, pupal mass is

55 often used as a proxy for fitness because larger females are generally more fecund (Honek, 
56 1993). In preparation for winter dormancy, many insects utilise specific energy storage

57 strategies, reviewed in detail elsewhere (Hahn and Denlinger, 2007, 2011). The stores used to

58 fuel metabolism are generally divided between lipid (usually fats in the form of triglycerides)

59 and carbohydrate (often as glycogen, but also as smaller molecules such as the disaccharide

60 trehalose). Many insects also utilise storage proteins (Burmester, 1999); however, although

61 storage proteins do have a role in diapause (Hahn and Denlinger, 2007), they do not appear to be

62 a primary source of energy for overwinter metabolism, and may instead be a route for transfer of

63 amino acids between larval and adult stages (e.g. O'Brien et al., 2002).

64

65 Lipids offer the most energy-dense storage, and empirical measurements of body composition

66 support the assumption that most non-feeding insects are consuming lipid (Sinclair et al., 2011).

67 However, insects that are frozen, encased in ice, or in an otherwise hypoxic environment will

68 likely rely on carbohydrate-fuelled anaerobic metabolism (Storey and Storey, 1986). Some

69 species, such as the spruce budworm Choristoneura fumiferana rely on carbohydrates over the

70 winter even when unfrozen (Han and Bauce, 1993), while others switch from lipids to other

71 energy sources mid-winter, possibly cued by diapause cessation (e.g. Adedokun and Denlinger,

72 1985; Yocum et al., 2005). Insects may shift their fuel use for other reasons; overwintering

73 insects are also water-stressed (Danks, 2000), and could therefore shift to carbohydrate

74 metabolism to liberate water hydrogen-bound to glycogen, as is seen in desiccation-tolerant

75 Drosophila (Marron et al., 2003).

76

\section{3. How do winter conditions drive energy use?}


78 Below the thermal optimum, there is usually a curvilinear relationship between enzyme-mediated 79 biological reactions and temperature (Schulte et al., 2011). Thus, warmer temperatures yield 80 higher rates of activity, development, growth, and metabolism (Fig. 2). During the winter, when 81 temperate insects generally are not actively growing, feeding, or developing, energy stores will 82 be consumed faster at higher temperatures. Consequently, winter energy use will be determined 83 by the mean temperature, the temperature variability, the length of winter, and the ability to 84 mitigate overwinter energy drain (Williams et al., in press).

86 Overwintering temperatures are modified by microhabitat. Persistent snow cover will usually 87 increase the mean temperature (potentially increasing energy use), but reduce the variability of 88 those temperatures (Pauli et al., 2013). Thermal variability is particularly important in 89 determining overwinter energy use because of the effect of Jensen's inequality (Fig. 3), whereby 90 an accelerating temperature-metabolic rate relationship results in an increased mean metabolic 91 rate (and energy consumption), because the high temperature portions of thermal cycles increase 92 metabolic rate more than the low temperature portions compensate by reducing energy 93 consumption (Ruel and Ayres, 1999; Williams et al., 2012b). Thus, thermal fluctuations, 94 especially to high temperatures, or about a warm mean, (e.g. during the autumn or spring) can 95 account for the majority of cumulative energy use during the dormant period (Sgolastra et al., 96 2011; Williams et al., 2012b; Fig. 3).

98 There are other potential forms of the relationship between temperature and energy consumption, 99 which may interact to produce a complex relationship (Fig. 2). In particular, there may be 
threshold changes in metabolic rate, as observed in freeze-tolerant caterpillars (Fig. 2B; Sinclair et al., 2004; discussed further in section 4.1), or transient cost of crossing thresholds, such as the

102 increased metabolic rate associated with recovery from chill coma (Macmillan et al., 2012b; Fig.

\section{Mitigating overwinter energy drain} the mean temperature, in thermal variability, and by snow cover (which will determine thermal variability and exposure to thermal extremes). Current climate change predictions do a poor job of predicting extreme temperatures and variability, and the scale of climate documentation is inappropriate for insects (Potter et al., 2013). Furthermore, snow cover is a combination of local and regional patterns of precipitation (Henry, 2008; Kreyling and Henry, 2011), in combination with localised topography that influences snow drift formation and therefore both snow depth and persistence (e.g. Scott et al., 2008). These microtopographical influences are hard to predict (Scherrer and Körner, 2010) and may mean that small changes in microhabitat selection could have a big influence on exposure to overwinter energy drain, just as behaviour is a key determinant of climate change impacts in the summer (Sunday et al., 2014). 


\section{4.1 Physiological mitigation of overwinter energy drain}

123 Insects can reduce overwinter energy drain by altering their temperature-energy use relationship through modified thermal sensitivity and/or suppressed metabolic rate, either of which reduces the rate of energy consumption (Fig. 4). Metabolic suppression can result from a temperatureindependent decrease in metabolic rate (decreasing the elevation of the temperature-metabolic rate relationship; Fig. 4B), or through temperature-dependent threshold decreases in metabolism, such as those observed upon freezing (Fig. 2B; Sinclair et al., 2004).

Temperature-independent metabolic suppression is a defining feature of diapause (Hahn and

132 insects with extreme metabolic suppression and deep diapause may therefore have relatively

133 little energy use over the duration of a winter, and be robust to increased winter temperatures

134 (e.g. Fründ et al., 2013; Williams et al., 2012a). Indeed, diapause-associated metabolic

135 suppression is such an effective energy conservation strategy that tropical insects can diapause at 136 high temperatures during the dry season with almost no reduction in fat content (Nedvěd and 137 Windsor, 1994). The mechanisms underlying metabolic suppression in diapausing insects are 138 beginning to be understood from a genetic level (Denlinger and Armbruster, 2014; Hahn and 139 Denlinger, 2011), but the metabolic biochemistry is not as well-explored as in some other taxa 140 (see Storey and Storey, 2004; Storey and Storey, 2007).

142 Temperature-metabolic rate relationships can change abruptly with temperature, such that 143 metabolic suppression is temperature-dependent (Fig. 2B). There are many potential causes of 
144 such thresholds; for example, Sinclair et al. (2004) suggest that failure of transmembrane ion 145 pumps at low temperature accounts for a threshold decrease in carbon dioxide emission when 146 Pringleophaga marioni caterpillars are cooled. The best-understood low temperature threshold shift in insects is probably the very clear physiological and biological threshold associated with ice formation in freeze-tolerant insects. While ice formation is usually restricted to extracellular spaces (but see Sinclair and Renault, 2010), the dehydration and changes in $\mathrm{pH}$ and oxygen delivery associated with being frozen lead to metabolic rate suppression, and there is often a consequent switch to carbohydrate-fuelled anaerobic metabolism (Storey and Storey, 2013). By contrast, insects that remain unfrozen in the cold do not experience such a threshold change in metabolic rate. Voituron et al. (2002) argued that this metabolic suppression could therefore provide a selective advantage for freeze tolerance. In vertebrates, the energetic costs of active responses to freezing and thawing do not support energy conservation when frozen (Sinclair et al., 2013). However, the duration of time spent frozen does appear to account for reduced overwinter energy use by Pyrrharctia isabella larvae overwintering in exposed microhabitats compared to thermally-buffered subnivean microhabitats (Marshall and Sinclair, 2012). Thus, this temperature-dependent metabolic suppression could be important for energy conservation by overwintering insects more generally.

Altered thermal sensitivity of metabolism changes the curvature of the temperature-metabolic rate relationship (Fig. 4). Both increased and decreased thermal sensitivity could be associated with overwintering. Increased thermal sensitivity would increase the energy savings at low temperatures, but carry the penalty of increased energy drain under variable conditions (Fig. 3). Increased thermal sensitivity could also be advantageous if it allows an overwintering insect to 
167 replenish energy stores during warm periods mid-winter, as is hypothesised for many insects in 168 the Southern Hemisphere (Sinclair et al., 2003). To my knowledge, there are no reports of 169 increased thermal sensitivity in overwintering insects (although few studies compare thermal 170 sensitivity among seasons), but this hypothesis could be tested through seasonal comparisons of 171 any species that exhibits winter activity and feeding, such as many New Zealand alpine insects 172 (Wharton, 2011). By contrast, decreased thermal sensitivity reduces the impact of Jensen's 173 inequality by decreasing the influence of high temperatures on metabolic rate (Fig. 3). For 174 example, overwintering larvae of Erynnis propertius (Lepidoptera: Hesperiidae) reared under 175 variable conditions decreased their thermal sensitivity of metabolic rate (Williams et al., 2012b). 176 This suppressed thermal sensitivity was fixed in populations from variable environments, but 177 phenotypically plastic in populations from stable environments, which suggests that thermal 178 sensitivity is under selection in direct response to the thermal variability of the environment. 179 However, modeling of energy consumption based on field temperatures showed that decreased 180 thermal sensitivity did not sufficiently compensate for high thermal variability, and that 181 populations from variable habitats had also accumulated more energy stores prior to 182 overwintering.

\subsection{Life history and behavioural mitigation of overwinter energy drain}

Changes to the life cycle, behaviour, and phenology are key means by which animals avoid or mitigate exposure to abiotic challenges (Huey and Tewksbury, 2009; Sunday et al., 2014; Tauber et al., 1986). Overwintering at life stages that permit replenishment of energy reserves therefore reduces the fitness effects of energy drain. For example, an insect that overwinters as an egg or early-instar larva can compensate for energetic drain over the winter by feeding in the growing 
190 season, whereas insects that overwinter as pupae or that pupate at the end of winter may have

191 limited opportunity to offset energetic drain. Similarly, insects such as mosquitoes, which feed

192 as adults to provision eggs, have opportunity to compensate for energy drain.

Overwinter phenology is an important determinant of overwinter energetics, particularly because it determines exposure to warm temperatures in the autumn and spring. For example, models of metabolic rate indicate that the bulk of energy used by diapausing E. propertius caterpillars is consumed during high temperatures experienced in the autumn (Williams et al., 2012b). Thus, shifting phenology such that diapause occurs later in the autumn could mitigate the effect of warmer or more variable autumns. However, in this example, the larvae are apparently constrained by the externalities of host plant quality and insufficient growing season to complete another flight (Prior et al., 2009), such that compensation for autumn phenology is achieved through a combination of decreased thermal sensitivity of metabolism and increased pre-winter energy stores (Williams et al., 2012b). Nevertheless, autumn phenology is clearly under selection: pitcher plant mosquitoes in North America have modified their autumn phenology in response to climate change (Bradshaw and Holzapfel, 2001), and delayed entry into winter diapause consumes energy reserves and decreases overwinter survival of Osmia lignaria bees (Sgolastra et al., 2011). Longer winters would also be expected to lead to increased energetic drain (Morris and Fulton, 1970). 
212 lead to energy savings in freeze-tolerant caterpillars (Marshall and Sinclair, 2012), and although

213 being buried in the soil leads to buffered, warm temperatures (e.g. Clarke et al., 2013), it also

214 prevents exposure to extreme high temperatures in autumn. However, insects cannot always

215 control the microclimate to which they are exposed. For example, Eurosta solidaginis (Diptera:

216 Tephritidae) larvae that overwinter above the snow use less energy than their below-snow

217 counterparts (Irwin and Lee, 2003), but wintering above or below snow is dependent on

218 stochastic events (whether or not the host plant falls over), rather than by any choice on the part

219 of the insect. In addition, microclimate temperatures can be variable over a short distance, and variation in snow cover or snow drifting could modify the success of microhabitat selection. For example, low altitude populations of the montane beetle Chrysomela aeneicollis are extirpated in years with reduced snow cover, possibly due to extreme low temperatures (Rank and Dahlhoff, 2002).

\section{Do energetics determine insect overwinter survival?}

226 Energetics takes a back seat to the abiotic stresses associated with exposure to low temperatures 227 in most considerations of insect overwintering (e.g. Denlinger and Lee, 2010; Leather et al., 228 1993). However, energetics could determine overwinter survival directly, because long winters 229 without resource depletion could lead to starvation, and indirectly, through a trade-off with 230 cryoprotection or because of the costs of repair of winter-associated damage. Overwinter 231 energetics could also affect development and reproduction at the conclusion of winter; these 232 effects of winter on growing-season performance are discussed in Section 6. 
234 The extent of overwinter energy drain can be driven by autumn energy use, winter energy use,

235 and also the duration of winter. In some cases, the duration of this winter energy drain does

236 directly limit survival and fitness; insects starve to death when they run out of resources. For 237 example, Morris and Fulton (1970) describe an 'optimal' length of winter for preserving energy

238 reserves in pupae of the fall webworm Hyphantria cunea, and there is some evidence that 239 overwintering $C$. fumiferana larvae die during extended winters when their carbohydrate reserves 240 have been consumed (Han and Bauce, 1998; Regniere et al., 2012). In these cases, strategies that 241 increase energy reserves at the start of overwintering, or that reduce depletion during winter, will 242 have a direct impact on survival (see sections 4.1 and 4.2).

The majority of insects accumulate low molecular weight cryoprotectants, usually polyols such as glycerol, prior to overwintering (Storey, 1997); thus, any trade-off between energy supply and cryoprotection may already have been decided at the beginning of winter. However, that tradeoff has the potential to be important: reduced cryoprotection could reduce probability of survival. For example, populations of the goldenrod gall fly E. solidaginis with lower haemolymph glycerol concentrations are also less cold-hardy (Williams and Lee, 2008). Some insects modify cryoprotectants in response to winter conditions. For example, E. solidaginis accumulates a full complement of glycerol (its primary cryoprotectant) prior to winter, but accumulates further sorbitol (as a secondary cryoprotectant) in response to cold stress (Storey and Storey, 1983). In this case, freezing leads to both cryoprotectant synthesis and carbohydrate metabolism, meaning that thermal stress is placing a dual load on the energy reserve. This competition between cryoprotection and metabolic fuel has been best-explored in freeze-tolerant wood frogs. In frogs, carbohydrate stores fuel metabolism during freezing, thawing, and while frozen, but also 
257 (through conversion to glucose) constitute the main cryoprotectant (Storey and Storey, 1985).

258 Thus, metabolic depletion of the carbohydrate pool could potentially compromise cryoprotection,

259 leading to a trade-off in fuel use (Sinclair et al., 2013) that could also underlie geographic

260 variation in the quantity of glycogen accumulated pre-winter in these frogs (Costanzo et al.,

261 2013). Perhaps because insects usually rely on lipid reserves for the bulk of their overwinter

262 energy demands, this potential cryoprotection-metabolism trade-off has received little attention

263 in insects.

264

265

266

267

268

269

270

271

272

273

274

275

276

277

278

279

Overwinter mortality from extreme cold events is usually fairly clear-cut (Bentz et al., 2010;

Virtanen et al., 1998), and aside from cryoprotection (see above), is likely unrelated to

energetics. However, the mechanisms underlying mortality during long, milder, winters have not been well-explored (Sømme, 1996). Under these conditions, longer winters not only lead to energy store depletion (Sgolastra et al., 2011), but also to the accumulation of chilling injuries (Koštál et al., 2006). It is not clear whether long winters lead to mortality solely because of resource depletion, entirely through accumulation of cold injuries, or perhaps due to an interaction. Interactions could be mediated in at least three ways. First, through a cryoprotectant-fuel trade-off (see above). Second, because energy depletion reduces cold tolerance at the end of winter via some other pathway, such as insulin signaling, which links energetics and physiological responses over winter (Sim and Denlinger, 2008). Third, because accumulated cold injuries demand additional energy for repair that is not available in energydepleted individuals. I suggest that these hypotheses could be readily tested in both field and laboratory settings, and that they could apply to insects utilising any cold tolerance strategy. 


\section{How are winter energetics and summer performance linked?}

281 With the exception of a few species that reproduce in the winter, the fitness consequences of 282 winter are relevant only in the context of their impacts on summer performance (Williams et al.,

in press). Throughout this review, I have assumed that more energy stores upon resumption of activity, growth and/or development equates with greater fitness, because larger individuals are more fecund (see also Honek, 1993). It is also possible that winter energetics may affect summer performance indirectly, and I develop an argument to this effect below.

Metabolic rate and energy stores are useful proxies for fitness because they can be used to represent the costs associated with an organism's maintenance and development, and the energy available for fitness-related activities. Thus, the argument goes: overwinter energy use, especially in species that have limited ability to replenish reserves post-winter, is a proxy for energy available for reproduction (which is a determinant of fitness). In some species, the relationship between energy use and reproductive output is easy to establish. For example, adults of the goldenrod gallfly $E$. solidaginis do not feed, and their oocytes can be easily counted (= potential fecundity), allowing a clear link to be made between energy use and fecundity (Irwin and Lee, 2000). Similarly, overwinter fat body depletion in the solitary bee $O$. lignaria is associated with decreased post-emergence longevity, and likely delayed egg maturation and reduced provisioning of offspring (Bosch et al., 2010). In other species, the assumptions have been less well-justified. For example, in my own work, we often measure pupal mass as a fitness proxy for Lepidoptera at the end of winter (e.g. Williams et al., 2012a; Williams et al., 2012b). However, with some exceptions (e.g. spruce budworm; K.E. Marshall \& B.J. Sinclair, in review) this proxy is based on relationships for other, distantly related species measured only during the 
growing season (e.g. Boggs and Freeman, 2005). Note that the majority of studies ignore the impact of winter on male condition, although male reproductive performance is important, and can be condition-dependent (e.g. Blanckenhorn and Hosken, 2003). Assuming a direct relationship between resource availability and reproductive output, longer, warmer, and more variable winters (all of which are potential consequences of climate change) will lead to increased energy use, and thus decreased fitness.

For many species, however, energy reserves at the conclusion of dormancy are not directly linked to fitness via resources because of the possibility of post-winter feeding. For example, $C$. fumiferana overwinters as a pre-feeding larva (Royama, 1984), many species overwinter as eggs (Danks, 2002), and Fründ et al. (2013) show that bees suffer more energy drain if they overwinter as adults than as larvae. Any links between winter and summer are generally then assumed to be driven by other sub-lethal impacts, for example via cold injury, perhaps to tissues associate with feeding (such as the gut), or because of the costs of damage repair (e.g. Izumi et al., 2005; Sinclair and Chown, 2005; Teets et al., 2011). However, because energy state is an integrator of winter conditions (Fig. 1), and energy balance and cryoprotectant management are closely associated with energy signaling pathways (Teets et al., 2012), one might also hypothesise that energy state could provide information about the nature of the winter experienced. This information could be transduced via insulin signaling, which can determine behaviour (e.g. Wigby et al., 2011), and is involved with regulation of diapause in various insects (e.g. Ragland et al., 2010). In addition, developmental conditions can determine adult metabolic rate and performance. For example, Le Lann et al. (2011) show an increased fecundity and metabolic rate (measured under common conditions) in parasitoid wasps reared at lower 
326 temperatures. This dependence of adult performance (and especially metabolism) on

327 developmental conditions provides another potential mechanism by which winter conditions

328 could drive summer performance, although the explicit role of overwinter energetics in

329 determining this relationship is not clear. In the context of closely connected ecosystems and 330 tight insect-host relationships, such information transfer between seasons could allow insects to 331 predict the performance of other species, and thus inform life-history decisions; to my 332 knowledge, this has not yet been investigated.

\section{Conclusions}

335 In conclusion, energy use is an important component of insect overwintering biology, and is 336 particularly relevant to understanding the potential impacts of changing thermal conditions with 337 climate change. There are a number of strategies insects can use to reduce overwinter energy 338 use, but little is known about the relative importance or phylogenetic distribution of these 339 strategies. Because the majority of overwinter energy consumption occurs in the warm periods 340 in autumn and spring when insects are dormant, this makes energy use particularly susceptible to 341 mismatches between (photoperiod-controlled) phenology and (temperature-controlled) winter 342 length. The links between winter energetics and mortality or summer performance have not been 343 well-established, and indirect relationships between energy use and fitness are particularly poorly 344 known. In sum, this speaks to a need to more rigorously involve physiology in ecological 345 studies, to do field studies on overwinter biology that can help to determine the proximate causes 346 of winter mortality, and to expand ecological studies to better understand links between winter 347 and the growing season. 
2

3

4348

34

○

1

12

13 14

15

\section{Acknowledgements}

350 Thanks to Caroline Williams (University of California at Berkeley) and Katie Marshall

351 (University of British Columbia) for many discussions about overwinter energetics, and Lauren

352 Des Marteaux and two anonymous referees for constructive criticism of an earlier draft of the 353 manuscript. My research on this topic has been supported over the years by Discovery Grants 354 from the Natural Sciences and Engineering Research Council (NSERC) of Canada. 


\section{References}

Adedokun, T.A., Denlinger, D.L., 1985. Metabolic reserves associated with pupal diapause in the flesh fly, Sarcophaga crassipalpis. J Insect Physiol 31, 229-233.

Bentz, B.J., Régnière, J., Fettig, C.J., Hansen, E.M., Hayes, J.L., Hicke, J.A., Kelsey, R.G., Negron, J.F., Seybold, S.J., 2010. Climate Change and Bark Beetles of the Western United States and Canada: Direct and Indirect Effects. Bioscience 60, 602-613.

Blanckenhorn, W.U., Hosken, D.J., 2003. Heritability of three condition surrogates in the yellow dung fly. Behav. Ecol. 14, 612-618.

Boggs, C.L., 2009. Understanding insect life histories and senescence through a resource allocation lens. Funct. Ecol. 23, 27-37.

Boggs, C.L., Freeman, K.D., 2005. Larval food limitation in butterflies: effects on adult resource allocation and fitness. Oecologia 144, 353-361.

Bosch, J., Sgolastra, F., Kemp, W.P., 2010. Timing of eclosion affects diapause development, fat body consumption and longevity in Osmia lignaria, a univoltine, adult-wintering solitary bee. J Insect Physiol 56, 1949-1957.

Bradshaw, W.E., Holzapfel, C.M., 2001. Genetic shift in photoperiodic response correlated with global warming. P Natl Acad Sci USA 98, 14509-14511.

Burmester, T., 1999. Evolution and function of the insect hexamerins. Eur J Entomol 96, 213 225.

Clarke, M.W., Thompson, G.J., Sinclair, B.J., 2013. Cold Tolerance of the Eastern Subterranean Termite, Reticulitermes flavipes (Isoptera: Rhinotermitidae), in Ontario. Environ. Entomol. 42, 805-810.

Costanzo, J.P., do Amaral, M.C.F., Rosendale, A.J., Lee, R.E., 2013. Hibernation physiology, freezing adaptation and extreme freeze tolerance in a northern population of the wood frog. J Exp Biol 216, 3461-3473.

Danks, H.V., 2000. Dehydration in dormant insects. J Insect Physiol 46, 837-852.

Danks, H.V., 2002. The range of insect dormancy responses. Eur J Entomol 99, 127-142.

Denlinger, D.L., Armbruster, P.A., 2014. Mosquito Diapause. Annu. Rev. Entomol. 59, 73-93.

Denlinger, D.L., Lee, R.E., 2010. Insect Low Temperature Biology. Cambridge University Press, Cambridge.

Fründ, J., Zieger, S.L., Tscharntke, T., 2013. Response diversity of wild bees to overwintering temperatures. Oecologia 173, 1639-1648.

Hahn, D.A., Denlinger, D.L., 2007. Meeting the energetic demands of insect diapause: Nutrient storage and utilization. J Insect Physiol 53, 760-773.

Hahn, D.A., Denlinger, D.L., 2011. Energetics of Insect Diapause. Annu. Rev. Entomol. 56, 103121.

Han, E.-N., Bauce, E., 1993. Physiological changes and cold hardiness of spruce budworm larvae, Choristoneura fumiferana (Clem.), during pre-diapause and diapause development under laboratory conditions. Can Entomol 125, 1043-1053.

Han, E.N., Bauce, E., 1998. Timing of diapause initiation, metabolic changes and overwintering survival of the spruce budworm, Choristoneura fumiferana. Ecol Entomol 23, 160-167.

Henry, H.A.L., 2008. Climate change and soil freezing dynamics: historical trends and projected changes. Clim. Change 87, 421-434.

Honek, A., 1993. Intraspecific variation in body size and fecundity in insects - A general relationship. Oikos 66, 483-492. 
Huey, R.B., Tewksbury, J.J., 2009. Can behavior douse the fire of climate warming? P Natl Acad Sci USA 106, 3647-3648.

Irwin, J.T., Lee, R.E., 2003. Cold winter microenvironments conserve energy and improve overwintering survival and potential fecundity of the goldenrod gall fly, Eurosta solidaginis. Oikos 100, 71-78.

Irwin, J.T., Lee, R.E., Jr, 2000. Mild winter temperatures reduce survival and potential fecundity of the goldenrod gall fly, Eurosta solidaginis (Diptera: Tephritidae). J Insect Physiol 46, 655-661.

Izumi, Y., Sonoda, S., Yoshida, H., Tsumuki, H., 2005. Identification of tissues showing the lowest tolerance to freezing in larvae of the rice stem borer, Chilo suppressalis. Physiol Entomol 30, 324-331.

Koštál, V., Yanagimoto, M., Bastl, J., 2006. Chilling-injury and disturbance of ion homeostasis in the coxal muscle of the tropical cockroach (Nauphoeta cinerea). Comp. Biochem. Physiol. B 143, 171-179.

Kreyling, J., Henry, H.A.L., 2011. Vanishing winters in Germany: soil frost dynamics and snow cover trends, and ecological implications. Clim. Res. 46, 269-276.

Le Lann, C., Wardziak, T., van Baaren, J., van Alphen, J.J.M., 2011. Thermal plasticity of metabolic rates linked to life-history traits and foraging behaviour in a parasitic wasp. Funct. Ecol. 25, 641-651.

Leather, S.R., Walters, K.F.A., Bale, J.S., 1993. The Ecology of Insect Overwintering. Cambridge University Press, Cambridge.

MacMillan, H.A., Williams, C.M., Staples, J.F., Sinclair, B.J., 2012a. Metabolism and energy supply below the critical thermal minimum of a chill-susceptible insect. J Exp Biol 215, 1366-1372.

Macmillan, H.A., Williams, C.M., Staples, J.F., Sinclair, B.J., 2012b. Reestablishment of ion homeostasis during chill-coma recovery in the cricket Gryllus pennsylvanicus. P Natl Acad Sci USA 109, 20750-20755.

Marron, M.T., Markow, T.A., Kain, K.J., Gibbs, A.G., 2003. Effects of starvation and desiccation on energy metabolism in desert and mesic Drosophila. J Insect Physiol 49, 261-270.

Marshall, K.E., Sinclair, B.J., 2010. Repeated stress exposure results in a survival-reproduction trade-off in Drosophila melanogaster. Proc. R. Soc. B 277, 963-969.

Marshall, K.E., Sinclair, B.J., 2012. Threshold temperatures mediate the impact of reduced snow cover on overwintering freeze-tolerant caterpillars. Naturwissenschaften 99, 33-41.

Morris, R.F., Fulton, W.C., 1970. Models for development and survival of Hyphantria cunea in relation to temperature and humidity. Memoirs of the Entomological Society of Canada, $1-60$.

Nedvěd, O., Windsor, D., 1994. Supercooling Ability, Fat and Water Contents in a Diapausing Tropical Beetle, Stenotarsus rotundus (Coleoptera, Endomychidae). Eur J Entomol 91, 307-312.

O'Brien, D.M., Fogel, M.L., Boggs, C.L., 2002. Renewable and nonrenewable resources: Amino acid turnover and allocation to reproduction in lepidoptera. P Natl Acad Sci USA 99, 4413-4418.

Pauli, J.N., Zuckerberg, B., Whiteman, J.P., Porter, W., 2013. The subnivium: a deteriorating seasonal refugium. Frontiers in Ecology and the Environment 11, 260-267. 
Potter, K.A., Woods, H.A., Pincebourde, S., 2013. Microclimatic challenges in global change biology. Glob. Change Biol.

Prior, K.M., Dzurisin, J.D.K., Pelini, S.L., Hellmann, J.J., 2009. Biology of larvae and adults of Erynnis propertius at the northern edge of its range. Can Entomol 141, 161-171.

Ragland, G.J., Denlinger, D.L., Hahn, D.A., 2010. Mechanisms of suspended animation are revealed by transcript profiling of diapause in the flesh fly. P Natl Acad Sci USA 107, 14909-14914.

Rank, N.E., Dahlhoff, E.P., 2002. Allele frequency shifts in response to climate change and physiological consequences of allozyme variation in a montane insect. Evolution 56, 2278-2289.

Regniere, J., St-Amant, R., Duval, P., 2012. Predicting insect distributions under climate change from physiological responses: spruce budworm as an example. Biol. Invasions 14, 15711586.

Royama, T., 1984. Population dynamics of the spruce budworm Choristoneura fumiferana. Ecol. Monogr. 54, 429-462.

Ruel, J.J., Ayres, M.P., 1999. Jensen's inequality predicts effects of environmental variation. Trends Ecol Evol 14, 361-366.

Scherrer, D., Körner, C., 2010. Infra-red thermometry of alpine landscapes challenges climatic warming projections. Glob. Change Biol. 16, 2602-2613.

Schulte, P.M., Healy, T.M., Fangue, N.A., 2011. Thermal Performance Curves, Phenotypic Plasticity, and the Time Scales of Temperature Exposure. Integr Comp Biol 51, 691702.

Scott, M.B., Dickinson, K.J.M., Barratt, B.I.P., Sinclair, B.J., 2008. Temperature and moisture trends in non-sorted earth hummocks and stripes on the Old Man Range, New Zealand: Implications for mechanisms of maintenance. Permafrost Periglac 19, 305-314.

Sgolastra, F., Kemp, W.P., Buckner, J.S., Pitts-Singer, T.L., Maini, S., Bosch, J., 2011. The long summer: Pre-wintering temperatures affect metabolic expenditure and winter survival in a solitary bee. J Insect Physiol 57, 1651-1659.

Sim, C., Denlinger, D.L., 2008. Insulin signaling and FOXO regulate the overwintering diapause of the mosquito Culex pipiens. P Natl Acad Sci USA 105, 6777-6781.

Sinclair, B., Addo-Bediako, A., Chown, S., 2003. Climatic variability and the evolution of insect freeze tolerance. Biol Rev 78, 181-195.

Sinclair, B.J., Bretman, A., Tregenza, T., Tomkins, J.L., Hosken, D.J., 2011. Metabolic rate does not decrease with starvation in Gryllus bimaculatus when changing fuel use is taken into account. Physiol Entomol 36, 84-89.

Sinclair, B.J., Chown, S.L., 2005. Deleterious effects of repeated cold exposure in a freezetolerant sub-Antarctic caterpillar. J Exp Biol 208, 869-879.

Sinclair, B.J., Klok, C.J., Chown, S.L., 2004. Metabolism of the sub-Antarctic caterpillar Pringleophaga marioni during cooling, freezing and thawing. J Exp Biol 207, 12871294.

Sinclair, B.J., Renault, D., 2010. Intracellular ice formation in insects: Unresolved after 50 years? Comp. Biochem. Physiol. A 155, 14-18.

Sinclair, B.J., Stinziano, J.R., Williams, C.M., MacMillan, H.A., Marshall, K.E., Storey, K.B., 2013. Real-time measurement of metabolic rate during freezing and thawing of the wood frog, Rana sylvatica: implications for overwinter energy use. J Exp Biol 216, 292302 . 
Sømme, L., 1996. The effect of prolonged exposures at low temperatures in insects. Cryo-Lett 17, 341-346.

Storey, J.M., Storey, K.B., 1983. Regulation of cryoprotectant metabolism in the overwintering gall fly larva, Eurosta solidaginis - Temperature control of glycerol and sorbitol levels. Journal of Comparative Physiology 149, 495-502.

Storey, J.M., Storey, K.B., 1985. Triggering of cryoprotectant synthesis by the initiation of ice nucleation in the freeze tolerant frog, Rana sylvatica. J. Comp. Physiol. B 156, 191-195.

Storey, J.M., Storey, K.B., 1986. Winter survival of the gall fly larva, Eurosta solidaginis Profiles of fuel reserves and cryoprotectants in a natural population. J Insect Physiol 32, 549-556.

Storey, K.B., 1997. Organic solutes in freezing tolerance. Comparative Biochemistry and Physiology 117A, 319-326.

Storey, K.B., Storey, J.M., 2004. Metabolic rate depression in animals: transcriptional and translational controls. Biol Rev 79, 207-233.

Storey, K.B., Storey, J.M., 2007. Tribute to P. L. Lutz: putting life on 'pause' - molecular regulation of hypometabolism. J Exp Biol 210, 1700-1714.

Storey, K.B., Storey, J.M., 2013. Molecular Biology of Freezing Tolerance. Comprehensive Physiology 3, 1283-1308.

Sunday, J.M., Bates, A.E., Kearney, M.R., Colwell, R.K., Dulvy, N.K., Longino, J.T., Huey, R.B., 2014. Thermal-safety margins and the necessity of thermoregulatory behavior across latitude and elevation. P Natl Acad Sci USA 111, 5610-5615.

Tauber, M.J., Tauber, C.A., Masaki, S., 1986. Seasonal Adaptations of Insects. Oxford University Press, New York.

Teets, N.M., Kawarasaki, Y., Lee, R.E., Denlinger, D.L., 2011. Survival and energetic costs of repeated cold exposure in the Antarctic midge, Belgica antarctica: a comparison between frozen and supercooled larvae. J Exp Biol 214, 806-814.

Teets, N.M., Peyton, J.T., Ragland, G.J., Colinet, H., Renault, D., Hahn, D.A., Denlinger, D.L., 2012. Combined transcriptomic and metabolomic approach uncovers molecular mechanisms of cold tolerance in a temperate flesh fly. Physiological Genomics 44, 764777.

Virtanen, T., Neuvonen, S., Nikula, A., 1998. Modelling topoclimatic patterns of egg mortality of Epirrita autumnata (Lepidoptera: Geometridae) with a geographical information system: predictions for current climate and warmer climate scenarios. J. Appl. Ecol. 35, 311-322.

Voituron, Y., Mouquet, N., de Mazancourt, C., Clobert, J., 2002. To freeze or not to freeze? An evolutionary perspective on the cold-hardiness strategies of overwintering ectotherms. Am Nat 160, 255-270.

Wharton, D.A., 2011. Cold tolerance of New Zealand alpine insects. J Insect Physiol 57, 10901095.

Wigby, S., Slack, C., Gronke, S., Martinez, P., Calboli, F.C.F., Chapman, T., Partridge, L., 2011. Insulin signalling regulates remating in female Drosophila. Proc. R. Soc. B 278, 424431.

Williams, C.M., Hellmann, J.J., Sinclair, B.J., 2012a. Lepidopteran species differ in susceptibility to winter warming. Clim. Res. 53, 119-130.

Williams, C.M., Henry, H.A.L., Sinclair, B.J., in press. Cold truths: how winter drives responses of terrestrial organisms to climate change. Biol Rev. 
Williams, C.M., Marshall, K.E., Macmillan, H.A., Dzurisin, J.D.K., Hellmann, J.J., Sinclair, 538 B.J., 2012b. Thermal variability increases the impact of autumnal warming and drives 539 metabolic suppression in an overwintering butterfly. Plos One 7, e34470.

540 Williams, J.B., Lee, R.E., 2008. Differences in cold tolerance, desiccation resistance, and $541 \quad$ cryoprotectant production between three populations of Eurosta solidaginis collected 542 from different latitudes. J. Comp. Physiol. B 178, 365-375.

543 Yocum, G.D., Kemp, W.P., Bosch, J., Knoblett, J.N., 2005. Temporal variation in overwintering 544 gene expression and respiration in the solitary bee Megachile rotundata. J Insect Physiol $545 \quad 51,621-629$. 
2

3

$4549 \quad$ Vita

550 Brent Sinclair graduated with his undergraduate and PhD degrees in Zoology from the

551 University of Otago, New Zealand under the supervision of David Wharton. He was a postdoc

552 with Steven Chown at the University of Stellenbosch, and then with Steve Roberts at the

553 University of Nevada, Las Vegas, before beginning at the University of Western Ontario in

554 2006, where he is now an Associate Professor and Faculty Scholar. Sinclair has received early

555 career awards from the Canadian Society of Zoologists and the Entomological Society of

556 Canada, and is a member of the Journal of Thermal Biology editorial board. 
Figure Captions

\section{Figure 1}

560 Schematic of sources and sinks of energy before, during, and after wintering in insects, and how 561 they might link to summer performance (which encompasses reproductive output and fitness).

562 Winter-specific processes are outlined with a dotted box; the dashed arrow from cryoprotection 563 to energy remaining reflects the use of cryoprotectants as a fuel at the end of winter.

\section{Figure 2}

565 Potential forms of relationships between Metabolic rate (MR) and temperature in insects. For 566 overwintering insects, metabolic rate determines energy consumption, so this is indicated as an 567 alternative quantity on the vertical axis. A) A 'normal' exponential relationship between 568 temperature and metabolic rate. B) A threshold (step) decrease in metabolic rate at a threshold 569 temperature, similar to that expected when an insect freezes. C) A transient energetic cost of 570 crossing a temperature threshold $\left(T_{\text {thresh }}\right)$, in this case during rewarming. Note that this cost may 571 be present in one direction but not the other; e.g. there is no energetic cost to cooling the fall 572 field cricket Gryllus veletis, while recovery from chill coma carries an energetic cost (MacMillan 573 et al., 2012a, b). D) A cumulative relationship between the number of threshold-crossing events 574 and energy use.

\section{Figure 3}

576 Thermal sensitivity of the metabolic rate-temperature relationship determines instantaneous 577 metabolic rate and daily energy use in ectotherms because of the disproportionate impact of 578 variability at high temperatures (Jensen's inequality). A) High (black), medium (grey) and low 579 (dotted) thermal sensitivities of the temperature-metabolic rate relationship. $\mu$ indicates the mean 
2

3

4

7

8

580 temperature (also on B). B) A daily thermal cycle. C) Instantaneous metabolic rates for the 581 thermal sensitivities in A across the daily cycle depicted in B. $\mu$ indicates the metabolic rate for

582 a constant temperature. D) Cumulative daily energy use for the instantaneous metabolic rates

583 shown in $\mathrm{C}$, with $\mu$ indicating the daily energy use from a constant temperature. The discrepancy

584 between the $\mu$ bar and the others indicates the impact of Jensen's inequality, while the

585 differences among the other bars indicates the impact of changing thermal sensitivity of

586 metabolic rate.

\section{$587 \quad$ Figure 4}

588 Modification of the metabolic rate (MR)-temperature relationship by insects. Metabolic rate 589 determines energy consumption in overwintering insects, so this is provided as an alternative 590 vertical axis. The normal metabolic rate-temperature relationship (black line, A) can be 591 suppressed by a simple change in elevation (grey line, B), be made more thermally sensitive (C), 592 which allows for a steeper decline in metabolic rate when temperature declines from the mean 593 (but increases cost of fluctuations to high temperatures), or be less thermally-sensitive (D), 594 reducing the impact of high temperatures on energy consumption. 


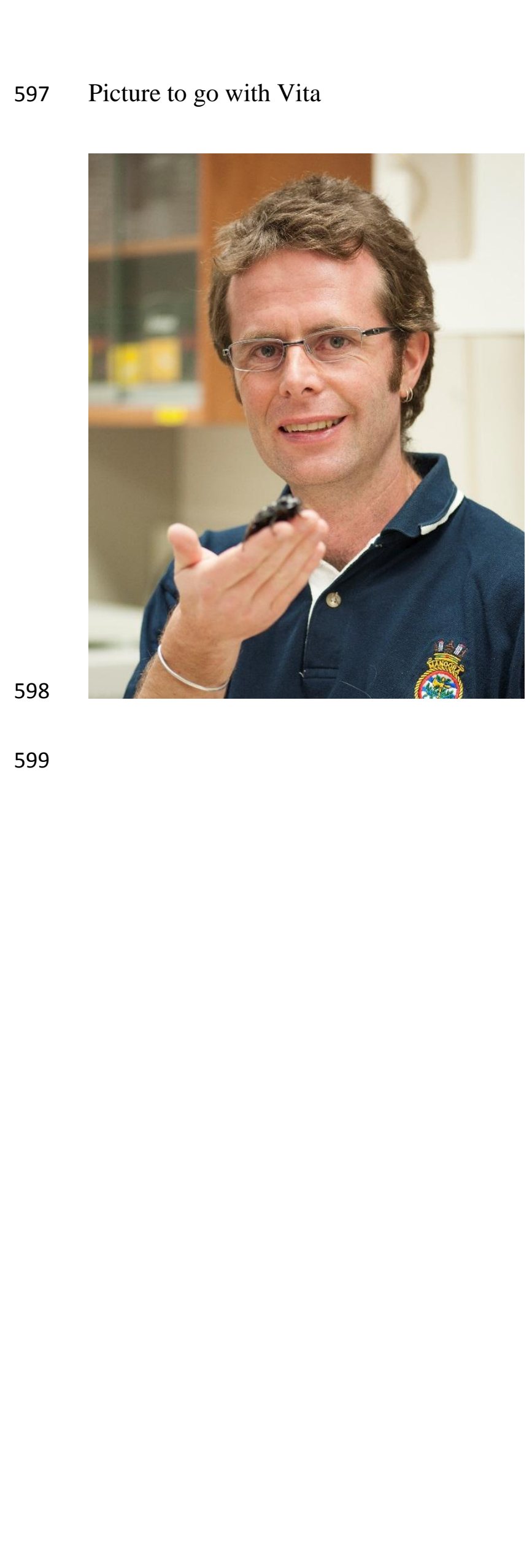




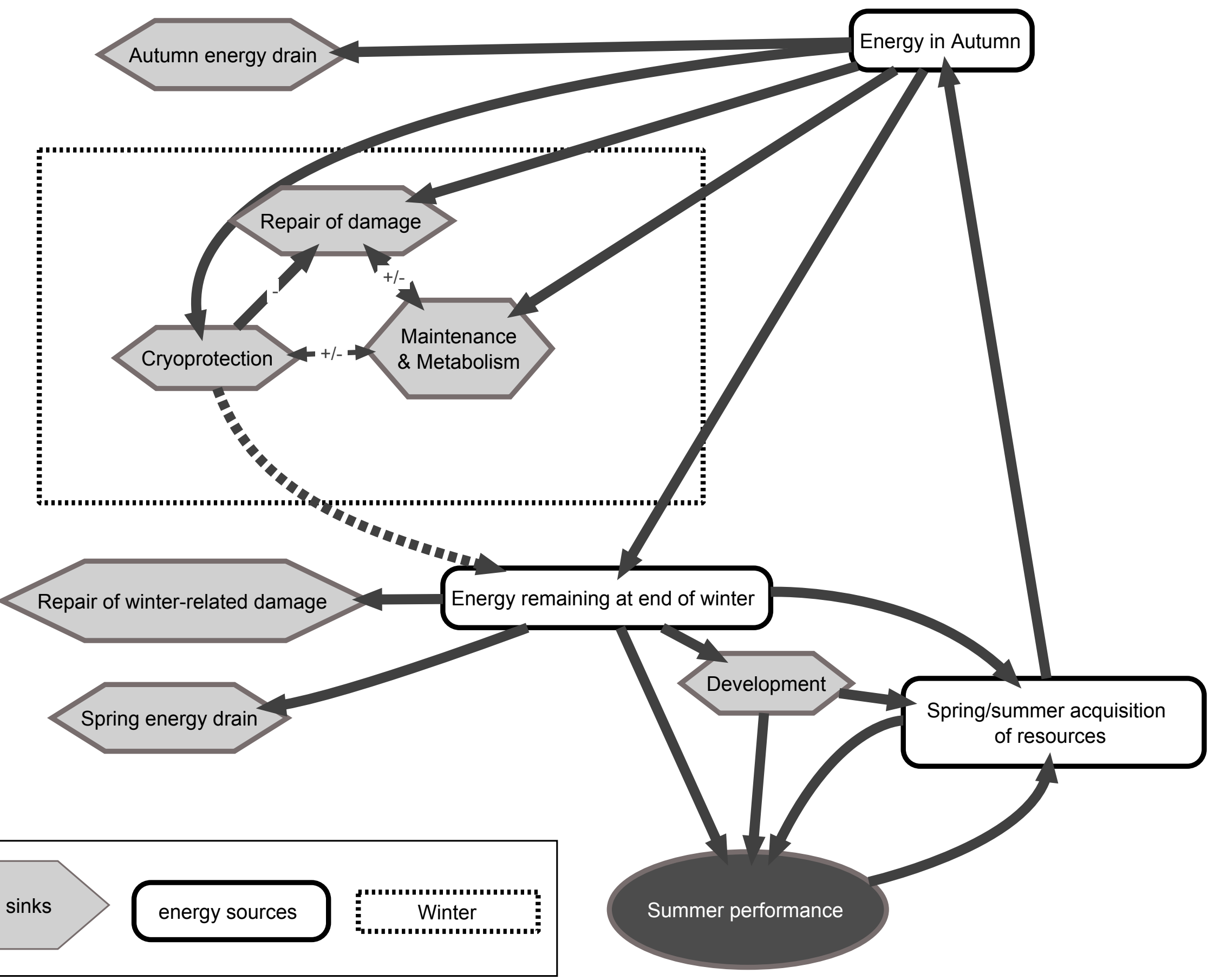



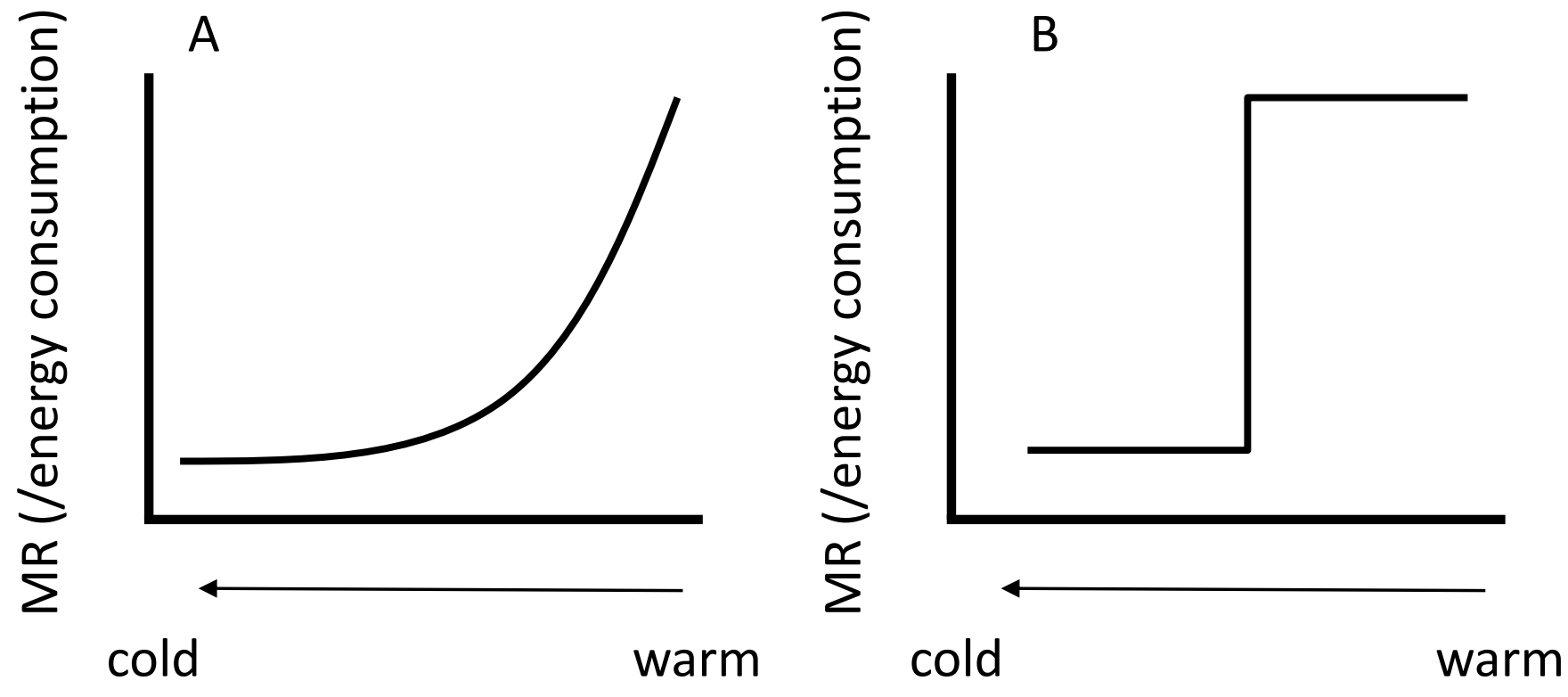

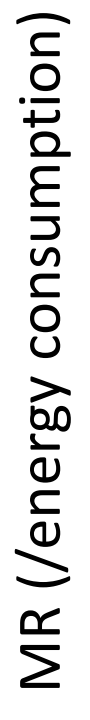
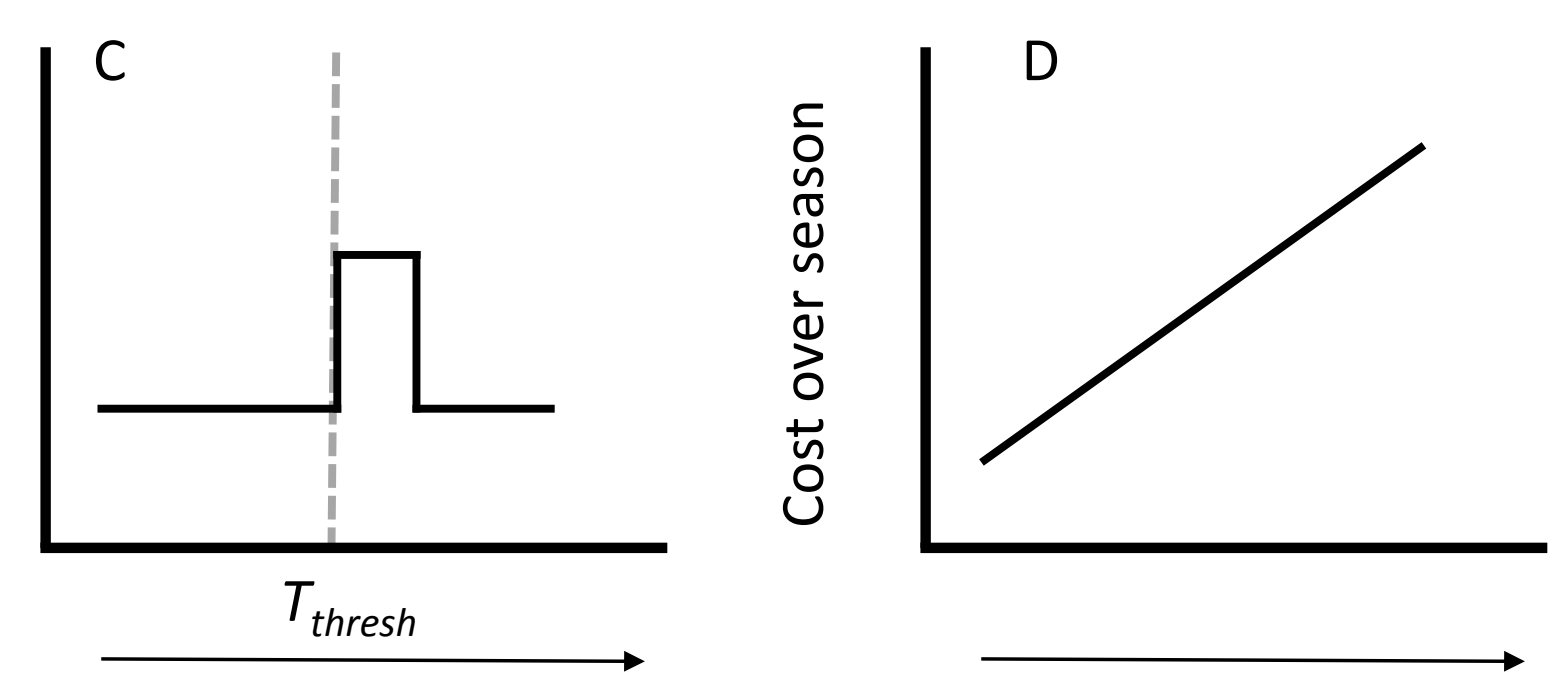

cold

warm 


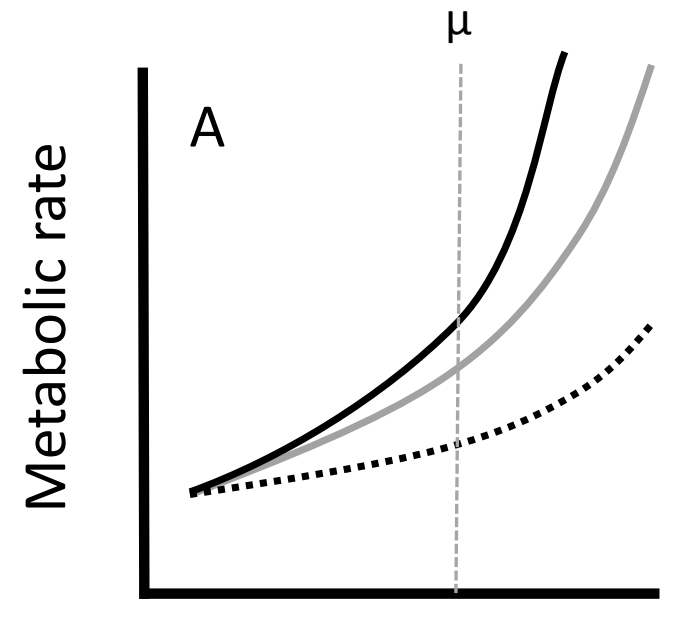

Temperature

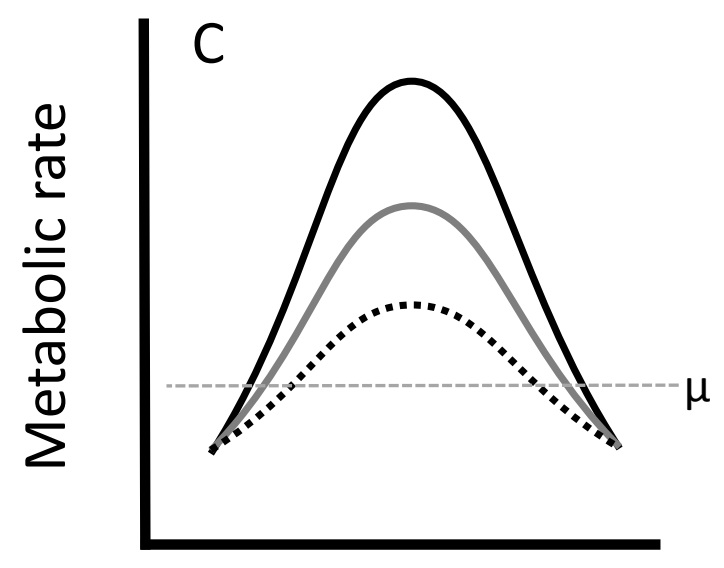

Time of day

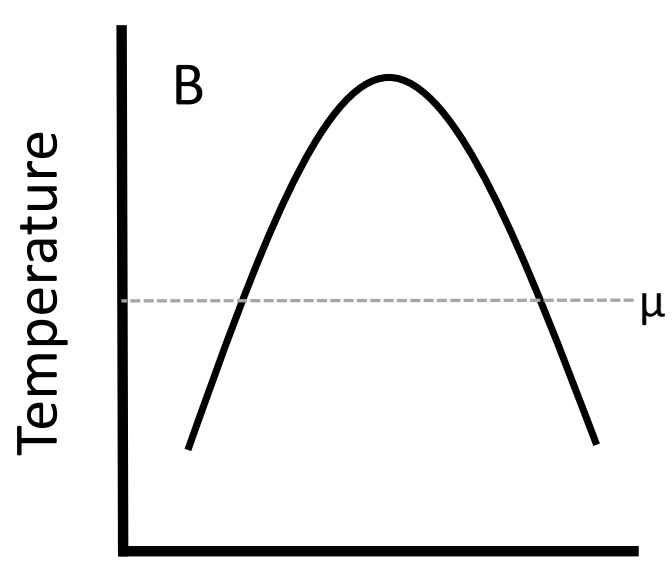

Time of day

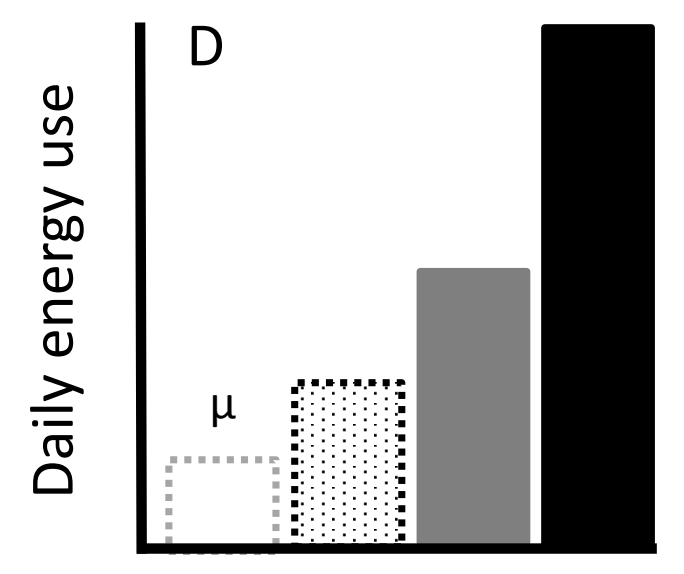

Thermal Sensitivity

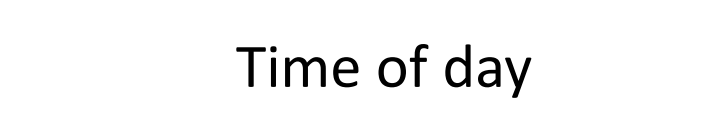




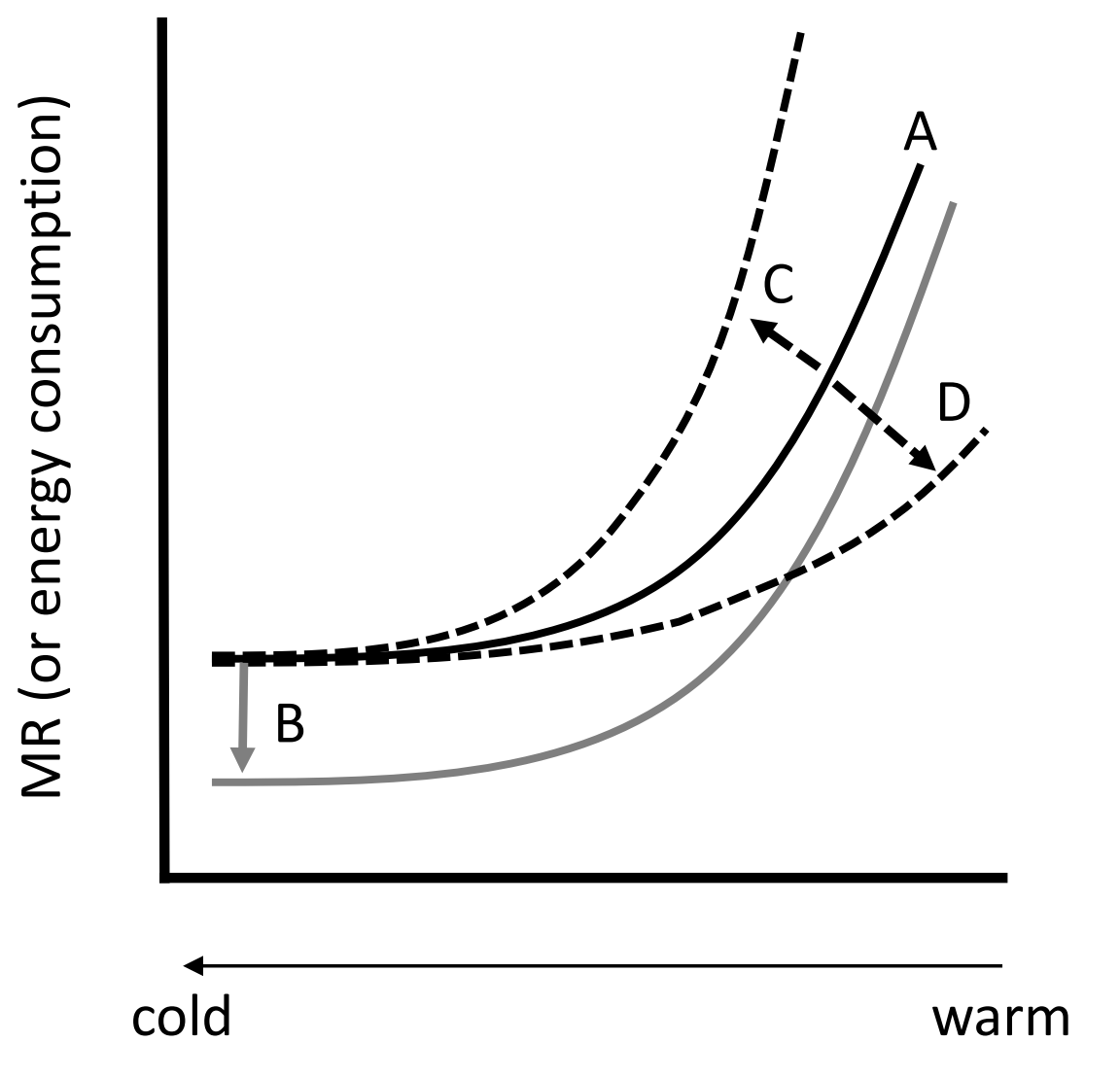
cold warm

\section{cld}
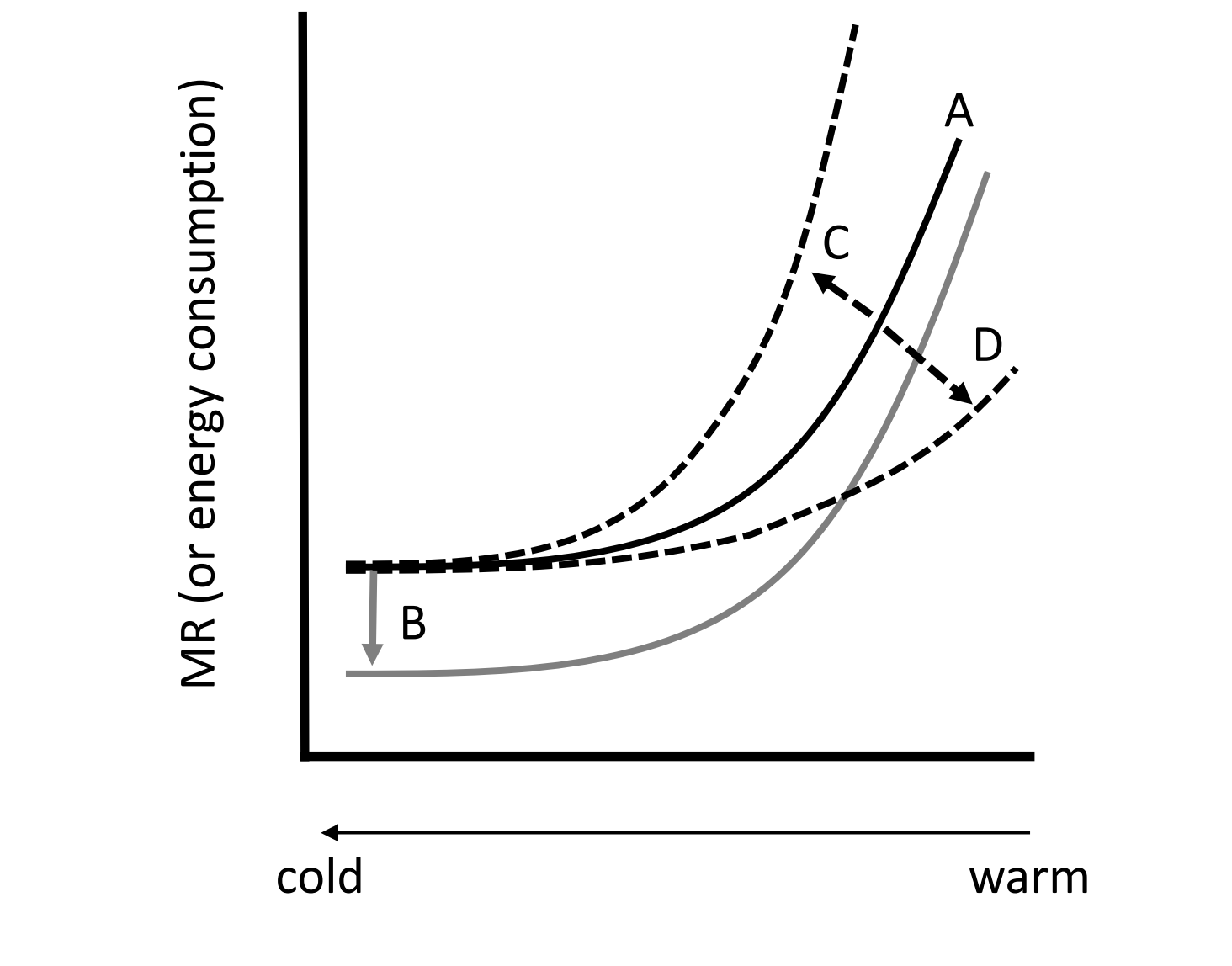